\title{
APORTE DA LEITURA NA PRÁTICA PEDAGÓGICA DOS PROFESSORES DE EDUCAÇÃO BÁSICA DO ESTADO DE PERNAMBUCO
}

\author{
Cleonice Nogueira Ferraz Porpino Estruc ${ }^{1}$
}

\section{RESUMO}

O ensino e o aprendizado da leitura são importantes não só para o enriquecimento da vida do aluno, mas também para a vida pessoal e profissional do educador. Portanto, devido à relevância da leitura na vida de mulheres e homens, há a necessidade de ampliar o conhecimento relacionado ao domínio da leitura, que é a justificativa para esse aprofundamento teórico. Assim, o objetivo deste artigo será investigar a contribuição da leitura na prática pedagógica dos professores da educação básica da Rede Estadual de Pernambuco, tendo como referência documentos oficiais fornecidos pela própria rede de ensino. O objetivo deste estudo é gerar referências para futuras pesquisas que envolvam o estado de Pernambuco como local de pesquisa.

Palavras-chave: Leitura; Prática Pedagógica; Rede Estadual de Pernambuco.

\begin{abstract}
Teaching and learning reading are important not only for the enrichment of the student's life, but also for the personal and professional life of the educator. Therefore, due to the relevance that reading in the lives of women and men, there is a need to expand the knowledge related to reading proficiency, which is the justification for this theoretical deepening. Thus, the aim of this article will be to investigate the contribution of reading in the pedagogical practice of basic education teachers of the State Network of Pernambuco, having as reference official documents provided by the teaching network itself. The aim of this study is to generate references for future research involving the state of Pernambuco as a research locus.
\end{abstract}

Keywords: Reading; Pedagogical Practice; State Network of Pernambuco.

\section{RESUMEM}

La enseñanza y el aprendizaje de la lectura son importantes no sólo para el enriquecimiento de la vida del estudiante, sino también para la vida personal y profesional del educador. Por lo tanto, debido a la relevancia que la lectura en la vida de mujeres y hombres, existe la necesidad de ampliar los conocimientos relacionados con el dominio de la lectura, que es la justificación de esta profundización teórica. Así, el objetivo de este artículo será investigar la contribución de la lectura en la práctica pedagógica de los docentes de educación básica de la Red Estatal de Pernambuco, teniendo como referencia documentos oficiales proporcionados por la propia red docente. El objetivo de este estudio es generar referencias para futuras investigaciones que involucren el estado de Pernambuco como lugar de investigación.

Palabras clave: Lectura; Práctica Pedagógica; Red Estatal de Pernambuco.

\footnotetext{
${ }^{1}$ Mestre em Ciências da Educação pela Universidad Autónoma de Assunción - Paraguai E-mail: cleoestruc@hotmail.com
}

Multifaces do Conhecimento Científico: Teoria e Prática 


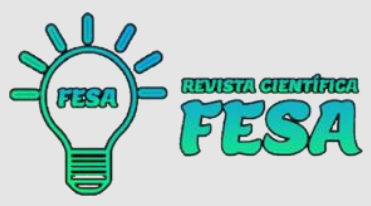

\section{INTRODUÇÃO}

A leitura está presente no cotidiano das pessoas em maior ou menor grau. Pressupõe-se que sua proficiência constitui um objetivo para a melhoria da qualidade de vida, empregabilidade do cidadão, dentre outros aspectos. Assim, a investigação dos fatores que consubstanciam à proficiência em leitura é de suma importância para direcionar práticas pedagógicas eficientes e eficazes no ensino da língua portuguesa e contribuirá de forma relevante no planejamento e na implementação de ações que supram a deficiência na formação do hábito de leitura.

Dessa maneira, Klein (2008, p. 41) relata que a escola precisa descobrir o sentido entre leitura e aprendizagem, consciente de ser o espaço possibilitador do acesso ao processo de produção do saber pessoal, numa atitude científica frente ao mundo que favorece à própria transformação. A escola precisa envolver-se com a leitura enquanto objeto de conhecimento, entendendo-a como processo de compreensão abrangente, cuja dinâmica envolve tanto componentes emocionais, intelectuais, fisiológicos, neurológicos, quanto culturais, econômicos e políticos. Logo, a solução para o desafio da formação de leitores na escola não está na mágica dos métodos de ensino, mas passa pela mudança de concepção que o professor tem sobre a leitura e que está na base de sua ação pedagógica.

A fim de fornecer parâmetros para que tal meta se efetive, a Rede Estadual de Educação do Estado de Pernambuco conta com diversas normativas oficiais que direcionam a prática dos professores no que tange ao fomento das práticas de leitura. Tal iniciativa, caracterizada como uma política pública voltada para a educação, é uma importante ação em prol da disseminação da leitura de forma sistematizada e fundamentada.

Assim, o presente artigo de vertente bibliográfico-documental tem a meta de investigar o aporte da leitura na prática pedagógica dos professores de educação básica da Rede Estadual de Pernambuco, tendo como referência documentos oficiais fornecido pela própria rede de ensino. Portanto, a fim de se alcançar essa meta, este corpus dividiu-se em diferentes eixos: Aspectos históricos; Base Curricular Comum de Pernambuco: língua portuguesa;

\section{Multifaces do Conhecimento Científico: Teoria e Prática}

Periódico Multidisciplinar da Facility Express Soluções Acadêmicas - ISSN: 2676-0428 
Parâmetros na sala de aula: língua portuguesa; e Orientações teóricometodológicas.

\section{ASPECTOS HISTÓRICOS}

No percurso da história da educação no Brasil, até os idos de 1970, o ensino sempre esteve voltado para atender a um número sempre restrito de alunos, vinculando-se a currículos cujos modelos amparavam-se no saber grecoromano.

Nos documentos norteadores do ensino da escrita e da leitura, os modelos eram sempre os eminentes autores clássicos da literatura brasileira e portuguesa. A oralidade, quando trabalhada, direcionava-se a discursos laudatórios, muito mais presos à escrita tradicional do que à fala propriamente dita.

Com a massificação da educação nos anos de 1970 em diante, a escola teve de lidar, de maneira abrupta, com um público diverso e, também, com uma enorme diversidade de competências, ao incorporar alunos das camadas menos favorecidas da sociedade, cuja forma e conteúdo de domínio da linguagem estavam muito longe dos pressupostos dos currículos tradicionais vigentes. (SALLA, 2012)

O resultado desse confronto foi uma viciada e indiferente maneira de lidar com o ensino da língua portuguesa, centrado, basicamente, na memorização de terminologias, no ensino de regras gramaticais, limitado ao domínio da frase, um projeto de ensino de leitura pouco produtivo e excludente, uma vez que não atendia às expectativas dos alunos das classes populares e de suas famílias.

Dos anos de 1980 em diante, fortes mudanças de foco no ensino da língua materna foram paulatinamente sendo implantadas, a partir da tomada do texto como unidade de ensino, da presença da oralidade, agora vista não como diferente da escrita, mas um contínuo dela, e da noção ampla dos gêneros do discurso. Com isso, ingressam na sala de aula gêneros textuais da realidade dos alunos, bem como a noção de suporte de gêneros, interlocução, interação social, texto como ambiente de interações sociais situadas.

\section{Multifaces do Conhecimento Científico: Teoria e Prática}




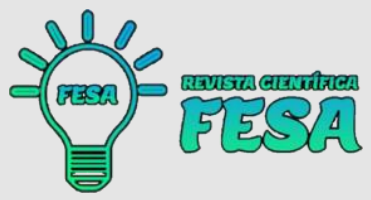

Diante de todas essas modificações, havia a expectativa de que se fomentasse muito mais um ensino de leitura efetivo e uma massificação dessa competência, haja vista a grande quantidade de pesquisa em voga.

Na década de 90, dentre as ações desenvolvidas pelo Mec/Inep, no sentido de minimizar difícil posição que a educação brasileira ocupa em nível mundial, está a criação do Sistema Nacional de Avaliação da Educação Básica (Saeb), iniciado em 1990 e a Prova Brasil implantada em 2005. Ambos com objetivo de avaliar a qualidade do ensino oferecido pelo Sistema Educacional Brasileiro, a partir de testes padronizados e questionários socioeconômicos, aplicados no quinto e no nono anos do ensino fundamental e terceiro ano do ensino médio, da disciplina Língua Portuguesa, com foco em leitura, como "um instrumento de medidas das competências leitora". (BRASIL, 2009, p. 6).

O Saeb e a Prova Brasil são os dois exames complementares que compõem o Sistema de Avaliação da Educação Básica. O Saeb, amparado pela Portaria n 931, de 21 de março de 2005, do Ministério da Educação do Brasil, é composto por dois processos: a Avaliação Nacional da Educação Básica (Aneb), realizada por amostragem das Redes de Ensino em cada unidade da Federação e pela Avaliação Nacional do Rendimento Escolar (Anresc), mais detalhada e extensa que a Aneb, que tem foco em cada unidade escolar e, por seu caráter universal, recebe o nome de Prova Brasil em suas divulgações (BRASIL, 2014).

O Ideb, um dos eixos do Plano de Desenvolvimento da Educação (PDE), lançado em 2007, pretende ser:

\footnotetext{
O termômetro da qualidade da educação básica em todos os estados, municípios e escolas do Brasil, combinando dois indicadores: fluxo escolar (passagem dos alunos pelas séries sem repetir, avaliado pelo Programa Educacenso) e desempenho dos estudantes (avaliado pela Prova Brasil nas áreas de Língua Portuguesa e Matemática). Para efetivar as ações do PDE, com a participação dos vários segmentos da sociedade foi criado o Plano de Metas. Esse plano estabelece um conjunto de diretrizes para que a União, os estados, o Distrito Federal e os municípios, em regime de colaboração, superem a extrema desigualdade de oportunidades existente em nosso país, com o objetivo de melhorar a educação de crianças, jovens e adultos brasileiros, tornando-os cidadãos críticos, reflexivos e conscientes dos seus direitos e deveres e da importância de sua participação no contexto local e global. (BRASIL, 2009, p. 4).
}

\section{Multifaces do Conhecimento Científico: Teoria e Prática}


Os dados dessas avaliações permitem definir ações para o aprimoramento da qualidade da educação no país, redução das desigualdades existentes e para o cálculo do Índice de Desenvolvimento da Educação Básica (Ideb), cujo objetivo é o de que, em 2022, bicentenário da nossa independência, a qualidade da educação do Brasil seja comparável à dos países desenvolvidos hoje. (PERNAMBUCO, 2014a, p. 3).

\section{BASE CURRICULAR COMUM DE PERNAMBUCO: LÍNGUA PORTUGUESA}

A Base Curricular Comum para as Redes Públicas de Ensino de Pernambuco (BCC-PE), elaborada em 2008, traz como opções de referência currículo, padrões e níveis de desempenho dos estudantes respaldados em documentos legais, nacionais e locais e que foram construídos nos últimos vinte anos, com as mobilizações e lutas de movimentos sociais organizados.

As bases legais da Proposta Curricular têm como respaldo a Carta Magna, a Constituição Federal Brasileira de 1988, que reconhece a educação como um direito social (art. $6^{\circ}$ ) de todos e dever do Estado e da família (art. 205), "devendo ser promovida e incentivada com a colaboração da sociedade, visando ao pleno desenvolvimento da pessoa, seu preparo para o exercício da cidadania e sua qualificação para o trabalho". Para a construção de uma base curricular comum, estabelece, em seu art. 210, que "serão fixados conteúdos para o ensino fundamental, de maneira a assegurar formação básica comum e respeito aos valores culturais e artísticos, nacionais e regionais".

A Constituição do Estado de Pernambuco/1989 (Cepe/1989), art. 176, o Estatuto da Criança e do Adolescente /1990 (Eca/1990), art. 53-54, e a Lei de Diretrizes e Bases da Educação Nacional/1996 (LDBEN/1996), art. 2o, apresentam pessoa, cidadania e trabalho como conceitos basilares que estão no foco da escolarização.

A BCC-PE enfoca a solidariedade como ideia de reconhecimento e de aliança a favor da vida em comum, que embasa uma condição de paradigma orientador da proposta curricular.

\section{Multifaces do Conhecimento Científico: Teoria e Prática}




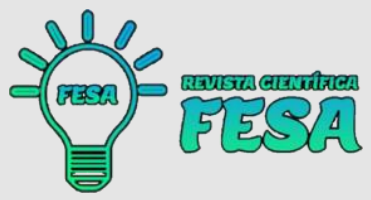

A LDBEN/1996, em seu art. 26, determina que "os currículos do ensino fundamental e médio devem ter uma base nacional comum, a ser complementada, em cada sistema de ensino e estabelecimento escolar, por uma parte diversificada, exigida pelas características regionais e locais da sociedade, da cultura, da economia e da clientela".

Complementa, também, conclamando que os currículos sejam norteados por diretrizes que venham assegurar a formação básica comum em todo o território nacional. Determina que é de competência dos estados federativos e com espírito flexível, transformar as diretrizes em propostas curriculares e, ao mesmo tempo, conjuntamente com as unidades escolares, complementá-las quanto à parte diversificada. Dessa forma, procura-se garantir a toda a sociedade a mobilização de conhecimentos relevantes, para se promover e ampliar o conjunto de saberes que respeitem a diversidade cultural.

A Base Curricular Comum apresenta um breve estudo de currículo, seus conceitos históricos e aplicações pelos teóricos que o estudam.

\begin{abstract}
A palavra currículo tem origem no latim - curriculum - que significa "corrida" ou "pista de corrida", sugerindo um percurso a ser seguido pelos estudantes; esse foi por bastante tempo o seu significado original. Foi a partir do século XVI, com o ingresso nas escolas de um contingente maior de estudantes, que os educadores se viram frente à necessidade de uma organização mais cuidadosa dos conteúdos e métodos de ensino (Santos, 2002). A ideia de currículo se disseminou, então, como sendo o elenco das disciplinas e de seus respectivos conteúdos, adotado pelos sistemas escolares, nos diferentes níveis de ensino, e assim permaneceu até fins do século XIX. (PERNAMBUCO, 2012b, p. 21).
\end{abstract}

Na difícil tarefa de construir o currículo em Pernambuco, se realizaram acordos que tornassem possível sua elaboração e implementação com a contribuição de todos os envolvidos no projeto: autoridades educacionais, Gerência Regionais de Educação, especialistas e professores, tendo-se em vista a possibilidade de que o que seria prescrito seria vivenciado.

Neste contexto, o currículo foi definido como "um conjunto de conhecimentos, habilidades e competências, traduzido em expectativas de aprendizagem". (PERNAMBUCO, 2012b, p. 23) As expectativas de aprendizagens do projeto geraram uma mudança de foco: substituiu

\title{
Multifaces do Conhecimento Científico: Teoria e Prática
}




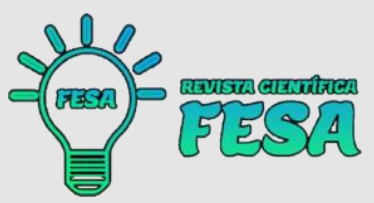

preocupação com a formação do professor pela preocupação com a aprendizagem do estudante. As expectativas de aprendizagens do currículo trazem alguns conceitos básicos de conhecimento, habilidades e competências.

$O$ documento realça os diferentes tipos de conhecimentos que se pode trabalhar na escola, sem discriminações. Para isso, discorre sobre a história do conhecimento desde a Antiguidade com o surgimento da filosofia, os filósofos e suas reflexões, chegando à atualidade com a teoria do conhecimento. Espaço de tempo em que se abrangem "mitos, do senso comum, do conhecimento religioso (fé), do conhecimento erudito e científico, da filosofia".

\section{PARÂMETROS NA SALA DE AULA: LÍNGUA PORTUGUESA}

A Secretaria de Educação do Estado de Pernambuco elaborou Parâmetros na Sala de Aula (PSA) como propostas que podem ser utilizadas pelo professor em todos os componentes curriculares da educação básica. Dispõe em seu site oficial o arquivo para download.

Esses parâmetros estão em consonância com Parâmetros Curriculares de Língua Portuguesa do Estado de Pernambuco para o ensino fundamental e médio e Parâmetros Curriculares Nacionais de Língua Portuguesa (para o Ensino Fundamental e Médio e Educação de Jovens e Adultos). Apresentam "propostas didáticas para a sala de aula (projetos didáticos, sequências didáticas, jornadas pedagógicas etc.) que abordam temas referentes aos diferentes componentes curriculares" (PERNAMBUCO, 2013f, p. 13).

Constituem um conjunto de orientações metodológicas que visam ser para o professor um instrumento orientador do planejamento e acompanhamento do processo de ensino e aprendizagem. Os parâmetros de Língua Portuguesa, (PCLP) de 2012, tem como foco principal o uso da língua, pois as práticas de linguagem na escola devem, desse modo, orientar-se para um conjunto de expectativas de aprendizagem organizadas em seis eixos - Apropriação do Sistema Alfabético (ASA), Análise Linguística ( $A L)$, Oralidade $(O)$, Leitura (L), Letramento Literário (LL) e Escrita (E). (PERNANBUCO, 2013f, p.15)

\section{Multifaces do Conhecimento Científico: Teoria e Prática}




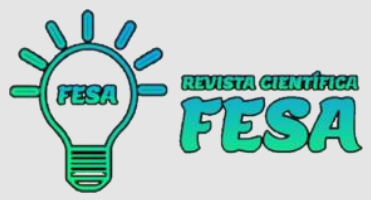

As atividades propostas ilustram e sugerem práticas de leitura, oralidade, escrita, de acordo com as propostas de concepções de ensino. As atividades apresentam algumas características, sendo uma delas a integração entre os eixos do currículo, um aspecto importante do modelo de ensino proposto nos PCLP /2012. A integração entre leitura e escrita na sala de aula se dá, por exemplo, porque a leitura e a análise de textos modelares é um procedimento didático dos mais relevantes no aprendizado da escrita. Por outro lado, em práticas de leitura, escrita, oralidade, e mesmo de letramento literário, os aprendizes estão, a todo tempo, procedendo à análise linguística, mobilizando e adquirindo conhecimentos sobre a linguagem. (PERNAMBUCO, 2013f, p. 15)

A prática da leitura e sua mediação, pelo professor, para a formação de leitores na escola, é uma das preocupações presentes nos parâmetros. Por isso, as atividades apontam para o exercício e o estímulo da leitura, em diferentes gêneros textuais, trabalhando sua estrutura tipológica, contextos de produção, objetivos específicos à comunicação e recursos utilizados em sua linguagem.

\section{ORIENTAÇÕES TEÓRICO-METODOLÓGICAS}

Com objetivo de melhorar a qualidade do ensino na rede estadual, a Secretaria de Educação de Pernambuco disponibiliza documentos que contêm as Orientações Teórico- Metodológicas (OTM) nas áreas de língua portuguesa, de matemática, de ciências naturais e de arte.

As orientações teórico-metodológicas da prática pedagógica do professor de Língua Portuguesa são voltadas para a formação de estudantes nos contextos de interação autor- texto-leitor e nas práticas socioculturais contemporâneas de usos da escrita". Os alunos, através do trabalho com os diferentes gêneros textuais, se expressam e criam os "sentidos que marcam as identidades individuais e sociais de uma comunidade determinada. (PERNAMBUCO, 2008b, p. 6).

As orientações definem os objetivos dos eixos organizadores das atividades em língua portuguesa, que são a produção e compreensão de textos orais para promover práticas de oralidade, orientando os alunos a identificar as relações entre linguagem oral e linguagem escrita e suas relações de

\section{Multifaces do Conhecimento Científico: Teoria e Prática}

Periódico Multidisciplinar da Facility Express Soluções Acadêmicas - ISSN: 2676-0428 


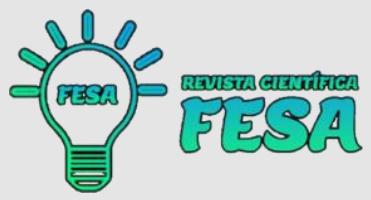

independência, de dependência e de interdependência; a leitura e a compreensão de textos a fim de aprofundar as habilidades de leitura, provendo situações em que os estudantes demonstrem compreensão sobre os textos que leem, refletindo, de forma contextualizada, sobre a gramática da língua, as características de cada gênero e tipo de texto, o efeito das condições de produção do discurso na construção do texto e de seu sentido; a produção de textos escritos com a meta de desenvolver nos estudantes habilidades de produzir textos escritos que exigem maior complexidade em sua elaboração, de gêneros variados e com diferentes funções, adequados aos interlocutores pretendidos, a seus objetivos, à natureza do assunto e às condições gerais de produção; a análise linguística e reflexão sobre a língua para proporcionar aos estudantes práticas de análise da língua em uso, visando à construção de conhecimentos sobre o funcionamento da linguagem, o sistema linguístico, as variedades da língua portuguesa, os diferentes registros, a partir de conhecimentos relevantes para as práticas de produção e recepção de textos; e o fomento à literatura em prol de propiciar aos estudantes a compreensão, pelo estudo do texto literário, das formas instituídas de construção do imaginário coletivo, do patrimônio representativo da cultura e das classificações preservadas e divulgadas, no eixo temporal e espacial, visando ao letramento literário daqueles estudantes. (PERNAMBUCO, 2008b, p. 6).

Para todas as séries/anos do ensino fundamental, as propostas de atividades foram elaboradas para as quatro unidades do ano letivo, orientando e ajudando o professor na sua prática docente.

De igual modo, o currículo de português para o ensino fundamental é um instrumento que auxilia o professor em sua rotina diária da prática pedagógica. Elaborado com base nos Parâmetros Curriculares do Estado de Pernambuco (PERNAMBUCO, 2013a). Os conteúdos apresentados estão em conformidade com os cinco eixos presentes nos Parâmetros Curriculares de Língua Portuguesa para a Educação Básica de Pernambuco: Análise Linguística, Oralidade, Leitura, Letramento Literário e Escrita. Para cada eixo relacionam-se as expectativas de aprendizagem com os seus respectivos conteúdos.

\section{Multifaces do Conhecimento Científico: Teoria e Prática}


Dois eixos, Escrita e Letramento Literário, são abordados numa segunda etapa do Currículo de Língua Portuguesa porque requerem do educando um olhar diferenciado uma maior compreensão literária e, nesta fase, ele aprofunda os processos da escrita e sua produção.

Assim, o currículo de português para o ensino fundamental se compõe de um conjunto de documentos elaborados pela Secretaria de Educação do Estado para auxiliar o professor no exercício da docência e para uma melhor qualidade na educação.

Em decorrência disso, o Sistema de Avaliação Educacional de Pernambuco (Saepe) materializa-se como uma ferramenta de avaliação e de monitoramento na área de educação do Estado de Pernambuco, apresenta informações importantes sobre o desempenho pedagógico dos estudantes das séries finais do ensino fundamental e médio e a participação das escolas, através da divulgação dos resultados da aplicação de testes nas disciplinas de língua portuguesa e matemática no segundo semestre de cada ano letivo.

O Saepe foi elaborado segundo os padrões utilizados pelo Centro de Políticas Públicas e Avaliação Educacional (Caed), instituição da Universidade Federal de Juiz de Fora (UFJF) que operacionaliza (elabora e desenvolve) programas estaduais e municipais destinados a mensurar o rendimento de estudantes de escolas públicas, como é o caso das escolas em estudo.

Para tanto, utiliza instrumentos tais como testes de proficiência e questionários, que permitem avaliar o desempenho escolar e os fatores, de dentro e de fora do meio escolar, associados ao mesmo, bem como medida e ferramenta para calcular a proficiência que representa um determinado traço latente (aptidão) de um aluno.

Assim sendo, pode-se dizer que o conhecimento de um aluno em determinada disciplina é um traço latente que pode ser medido através de instrumentos, compostos por itens elaborados a partir de uma matriz de habilidades.

\section{Multifaces do Conhecimento Científico: Teoria e Prática}




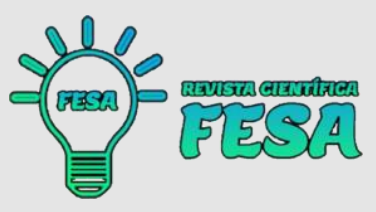

\section{CONSIDERAÇÕES FINAIS}

A leitura consta no cotidiano das pessoas em maior ou menor grau. Implicase que sua proficiência compõe um objetivo para a melhoria da qualidade de vida, empregabilidade do cidadão, dentre outros aspectos. Portanto, a investigação dos diretrizes reguladoras atuantes na rede estadual de educação de Pernambuco que levam à proficiência em leitura é de extrema importância para conduzir práticas pedagógicas eficientes e eficazes no ensino da língua portuguesa, contribuindo de forma relevante no planejamento e na implementação de ações que supram a deficiência na formação do hábito de leitura.

Portanto, os documentos orientam que as unidades escolares de Pernambuco devem dispor de textos/livros do interesse dos alunos, leitura de variados gêneros textuais e frequência às bibliotecas, incentivos ao uso dos livros didáticos e a consciência da importância da leitura na vida diária. Portanto, nota-se a referida rede caminha em direção virtuosa no que tange ao estímulo de práticas de leitura, tendo em vista que se deve, antes de tudo, direcionar as práticas docentes a fim de se assegurar a qualidade do ensino disponibilizado.

\section{REFERÊNCIAS BIBLIOGRÁFICAS}

BRASIL. Ministério da Educação. PDE - Plano de Desenvolvimento da Educação: SAEB: Ensino médio: matrizes de referências, tópicos e descritores. Brasília: Ministério da Educação. 2009.

BRASIL. Ministério da Educação. Instituto Nacional de Estudos e Pesquisas Educacionais Anísio Teixeira (INEP). Estatísticas educacionais. Indicadores dos Sistemas Educacionais Nacionais (INES). Recuperado de http://www.inep.gov.br/ .2014b.

BRASIL. Ministério da Educação. Instituto Nacional de Estudos e Pesquisas Educacionais Anísio Teixeira (INEP). Prova Brasil: Apresentações. Recuperado de http://www.inep.gov.br/ . $2014 \mathrm{f}$.

Brasil. Ministério da Educação. Instituto Nacional de Estudos e Pesquisas Educacionais Anísio Teixeira (INEP). O que é SAEB? Recuperado de http://www.inep. gov.br/ . 2014g.

KLEIN, L. Leitura e aprendizagem: Um binômio a ser

$$
\text { Multifaces do Conhecimento Científico: Teoria e Prática }
$$


descoberto pela escola. Revista Aprendizagem, 2 (9), p.41, 2008.

PERNAMBUCO. Secretaria de Educação. Base Curricular Comum para as Redes Públicas de Ensino de Pernambuco: Língua Portuguesa .Recife: Secretaria de Educação. 2008a.

PERNAMBUCO. Secretaria de Educação. Orientações Teórico-Metodológicas: Ensino Fundamental: Língua portuguesa, $1^{\circ}$ ao $9^{\circ}$ ano. Recife: Secretaria de Educação. 2008b.

PERNAMBUCO. Secretaria de Educação. (2012a). Parâmetros Curriculares da Educação Básica de Pernambuco: Parâmetros Curriculares de Língua Portuguesa para 0 Ensino Fundamental e Médio. Recuperado de http://www.educacao.pe.gov.br/portal/? pag=1\&cat=36\&art=1047 2012a.

PERNAMBUCO. Secretaria de Educação. (2012b). Parâmetros para a Educação Básica do Estado de Pernambuco: Parâmetros Curriculares. Recuperado de http://www.educacao.pe.gov.br/portal/upload/galeria/4171/parametros curricula res.concepcoes.pdf $2012 b$.

PERNAMBUCO. Secretaria de Educação. Currículo de Português para o Ensino Fundamental com base nos Parâmetros Curriculares do Estado de Pernambuco. Recife: Secretaria de Educação. 2013a.

PERNAMBUCO. Secretaria de Educação. (2014a). Avaliação das escolas estaduais e

bônus de desempenho educacional - BDE: Nota técnica. Recife: Secretaria de Educação. Recuperado de

http://www.educacao.pe.gov.br/diretorio/pmg2/nota tecnica idepe. pdf 2014a.

PERNAMBUCO. Secretaria de Educação. (2013f). Parâmetros para a Educação Básica do Estado de Pernambuco: Parâmetros na Sala de Aula: Língua Portuguesa. Ensino Fundamental e Médio. Recuperado de http://www.educacao.pe.gov.br/portal/ ?pag=1\&cat=36\&art=1047 $2013 f$.

SALLA, F. (2012, Junho/Julho). Conclusões da área sobre como o cérebro aprende trazem à tona questões tratadas por grandes teóricos da Psicologia, como Piaget, Vygotsky, Wallon e Ausubel: saiba como elas podem enriquecer as discussões sobre o ensino. Revista Nova Escola, (253), p.50-55, 2012.

\section{Multifaces do Conhecimento Científico: Teoria e Prática}

